\title{
PEMBUATAN VIRGIN COCONUT OIL (VCO) DENGAN METODE TANPA PEMANASAN SEBAGAI UPAYA MENINGKATKAN KESEHATAN MASYARAKAT
}

\section{MAKING VIRGIN COCONUT OIL (VCO) BY WITHOUT HEATING METHOD TO INCREASE THE PUBLIC HEALTH}

\author{
Oleh: \\ Teja Dwi Sutanto*, Agus Martono HP, Devi Ratnawati \\ Jurusan Kimia FMIPA Universitas Bengkulu \\ *Hp.081367722099, E-mail: tejads@unib.ac.id
}

\begin{abstract}
The aim of this activity was to training the manufacture of virgin coconut oil (VCO) with a without heating method to the community, especially the mother-housewife, resident of RT 12, Pematang Gubernur, Muara Bangkahulu, Bengkulu. As for the specific targets to be achieved in this activity was for the women, especially mothers, resident of RT 12 has the ability to produce VCO at least for their family, so that can improve the health and wellbeing of their family. The method used in achieving this goal was by lecture, discussion and practice of making VCO so that these activities target communities to be better understand the method of making VCO and can practice it theirself at home respectively
\end{abstract}

Keywords: Virgin Coconut Oil, without heating method, public health

\section{PENDAHULUAN}

Pembuatan minyak kelapa telah banyak dilakukan oleh masyarakat pedesaan di Indonesia sejak jaman dahulu, namun minyak kelapa yang dihasilkan masih mudah tengik. Disamping itu proses pembuatan yang dilakukan selama ini biasanya dengan cara pemanasan atau pengepresan sehingga perlu tenaga yang cukup banyak untuk melakukannya. Karena itu perlu dicoba untuk membuat minyak kelapa dengan prosedur yang lebih mudah, lebih murah, disamping produk minyak kelapa yang dihasilkan mempunyai kualitas yang lebih baik dan lebih berkhasiat obat.

Virgin coconut oil (VCO) atau kadang juga disebut minyak kelapa murni merupakan minyak kelapa yang mempunyai kandungan asam lemak rantai sedang atau medium chain fatty acids (MCFA) yang mudah diurai oleh tubuh dengan jumlah yang sangat tinggi. Disamping itu VCO juga mempunyai kandungan antioksidan seperti tokoferol dan betakaroten yang sangat tinggi. Karena banyaknya kandungan MCFA dan antioksidan dalam VCO, maka minyak ini dapat digunakan untuk menjaga kesehatan tubuh serta menangkal berbagai penyakit berbahaya seperti penyakit jantung, kolesterol dan stroke (Hegde, 2006; Snowdon dkk, 2003). Disamping itu kandungan asam laurat yang tinggi dalam VCO menyebabkan minyak ini dapat berfungsi sebagai antivirus, antibakteri dan antiprotozoa (Setiaji dan Prayogo, 2006, Setiaji, 2013). Kandungan serta manfaat yang 
sangat bagus dari VCO tersebut belum banyak diketahui oleh masyarakat umum, khususnya masyarakat Desa Pematang Gubernur, Kota Bengkulu.

Mengingat manfaat yang sangat banyak dari VCO bagi kesehatan, maka perlu diadakan pelatihan untuk membuat VCO dengan metode yang sederhana namun menghasilkan VCO dengan kualitas yang baik kepada masyarakat khususnya ibu-ibu rumah tangga di lingkungan RT 12 Desa Pematang Gubernur, Kota Bengkulu.

\section{METODE PENGABDIAN}

Kegiatan ini dimulai dengan ceramah untuk menjelaskan kepada ibu-ibu sasaran kegiatan ini mengenai VCO dan manfaatnya bagi kesehatan serta bagaimana cara membuat VCO agar diperoleh kualitas yang baik. Selanjutnya diberikan kesempatan kepada ibu-ibu rumah tangga peserta kegiatan ini untuk menanyakan yang belum jelas mengenai VCO dan cara pembuatannya yang akan dilakukan dalam kegiatan ini.

Langkah berikutnya adalah praktek pembuatan VCO dengan metode tanpa pemanasan untuk mempraktekkan metode pembuatan VCO yang sudah dijelaskan bersama-sama dengan ibu-ibu rumah tangga sasaran kegiatan ini. Metode ini dimulai dengan pemarutan kelapa, pembuatan santan kanil (krim santan) dan kemudian pembuatan VCO dengan metode tanpa pemanasan untuk mendapatkan VCO dengan kualitas yang baik. Secara skematis metode pembuatan VCO yang dilakukan terlampir.

\section{HASIL DAN PEMBAHASAN}

Berdasarkan pengamatan yang dilakukan sesudah pelaksanaan kegiatan pengabdian pada masyarakat ini terlihat bahwa masyarakat khususnya ibu-ibu warga RT 12 Kelurahan Pematang Gubernur, Kecamatan Muara Bangkahulu, Kota Bengkulu terlihat sangat antusias mengikuti seluruh kegiatan ini mulai dari penjelasan hingga praktek pembuatan VCO dengan metode tanpa pemanasan. Antusiasme masyarakat ini terlihat dari banyaknya peserta yang hadir yaitu hampir seluruh ibu-ibu warga RT 12 ikut menghadiri kegiatan ini. Antusiasme masyarakat ini juga ditunjukkan dengan banyaknya pertanyaan pada sesi diskusi yang berkaitan dengan pembuatan VCO dan pemanfaatannya untuk kesehatan. Keadaan ini disebabkan karena masyarakat khususnya ibu-ibu warga RT 12 merasa mendapatkan tambahan pengetahuan baru yang sangat bermanfaat yang langsung bisa diparaktekkan dengan menggunakan bahan-bahan yang sudah dikenal dan dapat diperoleh dengan mudah dilingkungan sekitarnya, yaitu teknologi sederhana pembuatan VCO dengan metode tanpa pemanasan yang berbeda dengan yang sudah dikenal selama ini. Pengetahuan tersebut dapat melengkapi pengetahuan mengenai teknik pembuatan minyak kelapa yang biasa dilakukan masyarakat yaitu dengan pemanasan, disamping itu dapat dijadikan sebagai alternatif teknologi pembuatan minyak kelapa yang sangat baik untuk kesehatan masyarakat.

Masyarakat sasaran terlihat sangat antusias dalam mengikuti pelatihan pembuatan 
VCO dengan metode tanpa pemanasan yang diberikan tim sehingga sesudah mengikuti pelatihan yang diberikan pada kegiatan ini ibu-ibu warga RT 12 Kelurahan Pematang Gubernur, Kecamatan Muara Bangkahulu, Kota Bengkulu sangat antusias untuk dapat membuat sendiri VCO dengan metode yang disampaikan dengan menggunakan peralatan sederhana yang sudah tersedia di rumah masing-masing. Hal ini disebabkan karena alat dibutuhkan untuk membuat VCO dengan metode ini menggunakan teknologi yang sangat sederhana dan mudah dimengerti oleh masyarakat. Disamping itu berdasarkan penjelasan yang diberikan, alat-alat yang dibutuhkan tersebut semuanya sudah tersedia di rumah yaitu berupa toples, saringan kelapa, corong dan selang. Bahan yang digunakan juga dapat diberoleh dengan sangat mudah di pasar karena biasa digunakan untuk keperluan seharihari.

Dari percobaan pembuatan VCO yang dilakukan ternyata setiap 10 butir kelapa yang digunakan diperoleh VCO sebanyak $\pm 1000 \mathrm{ml}$. Disamping itu masih dihasilkan minyak goreng sehat (Healthy Coconut Oil HCO) jika blondo yang diperoleh sedikit dipanaskan, selanjutnya blondo yang sudah tidak menghasilkan minyak yang masih berwarna putih dapat digunakan untuk membuat tepung. Hal ini tentu saja sangat menguntungkan karena disamping diperoleh VCO yang mempunyai nilai jual tinggi (Rp. 30.000,- setiap $100 \mathrm{ml}$ ) dan dapat digunakan untuk pengobatan berbagai penyakit, juga diperoleh minyak goreng sehat (HCO) dan blondo yang dapat digunakan untuk membuat tepung, sehingga secara ekonomis sangat menguntungkan masyarakat (Setiaji dan Prayogo, 2006).

\section{KESIMPULAN DAN SARAN}

\section{Kesimpulan}

Berdasarkan hasil pelaksanaan kegiatan pengabdian pada masyarakat ini, maka dapat dibuat kesimpulan sebagai berikut:

1. Masyarakat Bengkulu, khususnya ibu-ibu warga RT 12 Kelurahan Pematang Gubernur, Kecamatan Muara Bangkahulu, Kota Bengkulu belum mengetahui berbagai manfaat yang sangat baik dari VCO bagi kesehatan.

2. Masyarakat Bengkulu khususnya ibu-ibu warga RT 12 Kelurahan Pematang Gubernur, Kecamatan Muara Bangkahulu, Kota Bengkulu dapat membuat sendiri VCO dengan teknologi sederhana dan dengan alat-alat rumah tangga yang ada di rumahnya..

3. Dengan membuat sendiri VCO di rumahnya maka masyarakat Bengkulu khususnya ibu-ibu warga RT 12 Kelurahan Pematang Gubernur, Kecamatan Muara Bangkahulu, Kota Bengkulu akan dapat meningkatkan kesehatan keluarganya disamping meningkatkan penghasilan keluarganya yang akhirnya akan dapat meningkatkan kesehatan masyarakat.

\section{Saran}

1. Perlu dilakukan pemasyarakatan lebih lanjut mengenai pembuatan VCO dengan metode tanpa pemanasan dengan sasaran masyarakat yang lebih luas. 
i. Perlu dilakukan pemasyarakatan mengenai pemanfaatan VCO untuk meningkatkan kesehatan masyarakat, khususnya bagi masyarakat Bengkulu.

\section{UCAPAN TERIMA KASIH}

Dengan terlaksananya kegiatan ini perlu kami sampaikan ucapan terima kasih yang sebesar-besarnya kepada:

1. Ketua LPPM Universitas Bengkulu yang telah memberikan surat tugas untuk pelaksanaan kegiatan ini sehingga kegiatan ini dapat kami laksanakan dengan lancar.

2. Ketua RT 12 Kelurahan Pematang Gubernur, Kecamatan Muara Bangkahulu yang telah memberi izin beserta ibu-ibu warga Rt 12 yang telah mengikuti kegiatan ini dengan antusias sehingga kegiatan ini dapat berjalan dengan lancar.

\section{DAFTAR PUSTAKA}

Hegde, B.M., 2006, Coconut Oil - Ideal Fat next only to Mother's Milk, Journal, Indian Academy of Clinical Medicine, 7(1): 16-9,

Setiaji, B., dan Prayogo, S., 2006, Membuat VCO Berkualitas Tinggi, Penebar Swadaya, Jakarta.

Setiaji, B., 2013, Coco Power, Model Pemberdayaan Masyarakat Petani Kelapa, Coco Power Press, Yogyakarta.

Snowdon, W., Osborn, T., Aarlbersberg, B., and Jimaima Schultz, J., 2003, COCONUT Its role in health, Secretariat of the Pacific Community Cataloguing-in-publication data, Pacific Island. 
Lampiran: Gambar skematis metode pembuatan VCO

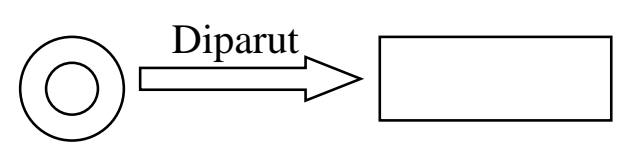

Buah kelapa

Kelapa Parut

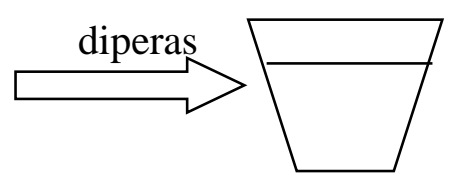

Santan Kelapa
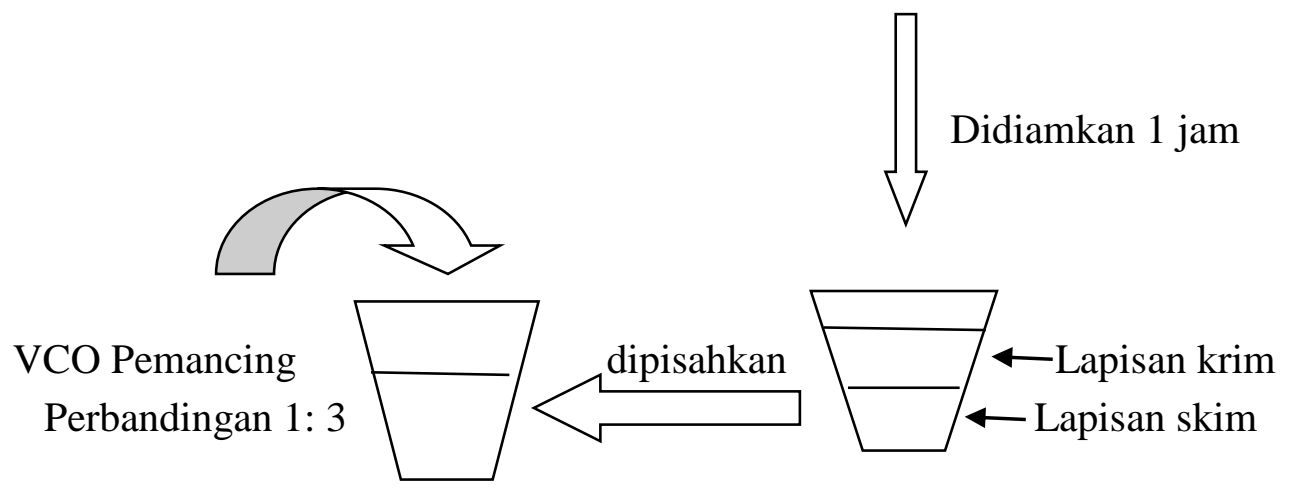

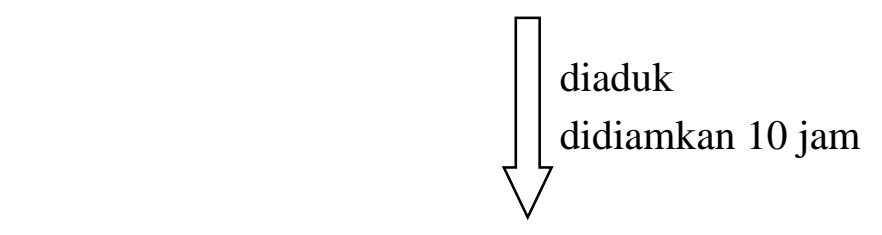
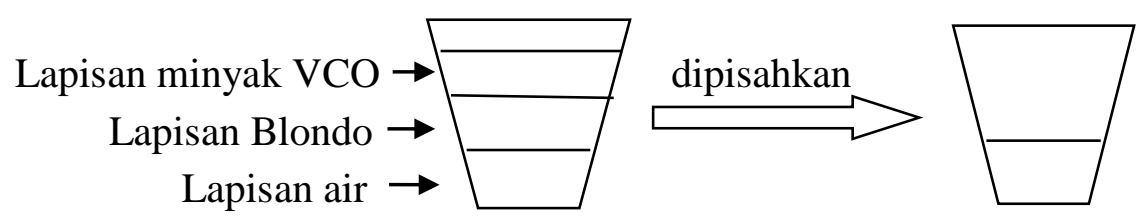

Lapisan VCO

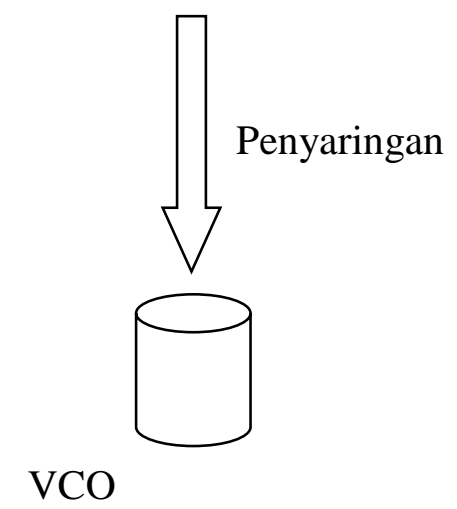

